\title{
Estimating local bed shear stress from velocity observations
}

\author{
Peter R. Wilcock \\ Department of Geography and Environmental Engineering, Johns Hopkins University, Baltimore, Maryland
}

\begin{abstract}
Replicate velocity observations using conventional equipment under typical field conditions are used to evaluate the precision of different methods for estimating local boundary shear stress from velocity measurements. The bed shear velocity $u_{*}$ can be estimated within $3 \%$ using the depth-averaged velocity in the vertically averaged logarithmic velocity profile. To be accurate, this method is limited to relatively simple flow geometries which may be expected to have the appropriate velocity structure. Estimates of $u_{*}$ made using a single near-bed velocity observation are less precise by a factor of 3 because of the larger uncertainty associated with a single observation. Accuracy of this method requires appropriate flow conditions only near the bed, so it may be applied in a wider range of flow conditions, including spatially variable flow. Estimates of $u_{*}$ from the slope of the near-bed velocity profile are the least precise and require the most restrictive flow conditions for accuracy but offer the advantage that they may be made without independent knowledge of the bed roughness.
\end{abstract}

\section{Introduction}

Boundary shear stress in rivers cannot be measured directly but is estimated from observations of velocity or flow geometry and their relation with the boundary shear stress. Values of local shear stress $\tau_{0 \ell}$ (corresponding approximately to a bed area containing a few dozen of the coarser grains on the bed surface) are most directly estimated from observations of velocity above that portion of the bed. With no direct measurement the accuracy of $\tau_{0 \ell}$ estimates cannot be evaluated directly but can be assessed using empirical and theoretical analogy with similar flow geometries for which $\tau_{0}$ is known. Evaluation of the precision of $\tau_{0 \ell}$ estimates is possible using replicate observations made under constant conditions, although such measurements are rarely made due, in part, to logistical restrictions and the typical variation of flow and sediment transport in time and space.

The clearest reason for reliable estimates of $\tau_{0 \ell}$ is to calculate the transport field and the related scour, deposition, and channel change. Because rates of sediment transport increase in a rapid and nonlinear fashion with $\tau_{0 \ell}$, even apparently modest error in $\tau_{0 \ell}$ can produce substantial error in calculated transport rates, particularly at conditions near the onset of grain motion. The same problem applies to spatial variability in $\tau_{0 \ell}:$ the sum of local transport rates (calculated from $\tau_{0 \ell}$ ) across a section may be substantially different from the total load calculated using the section-averaged shear stress, even for sections with simple prismatic topography. Reliable estimates of $\tau_{0 \ell}$ are needed not only to resolve the local transport field but to determine spatially integrated transport rates.

In this paper, replicate observations are used to evaluate the precision of different methods for estimating $\tau_{0}$ from velocity observations. Conventional equipment was used under typical field conditions on a large gravel-bed river. Repeat observations under identical conditions were made possible by a constant discharge reservoir release that produced negligible bedmaterial transport. Information on the error associated with

Copyright 1996 by the American Geophysical Union.

Paper number 96WR02277.

0043-1397/96/96WR-02277\$09.00 different methods for estimating $\tau_{0 \ell}$ should be useful in judging the precision of estimates made under similar conditions. These estimates of precision, together with considerations of convenience and model accuracy, provide the basis for selecting the most appropriate or advantageous method for different conditions and purposes.

\section{Available Methods}

A number of methods are available for estimating $\tau_{0 \ell}$ from field observations (see review by Dietrich and Whiting [1989]). Some of these methods, such as measurement of the near-bed turbulence or the divergence of the depth-averaged velocity field, require precision or techniques that are not generally feasible under typical field conditions [e.g., Whiting and Dietrich, 1991]. Estimates of $\tau_{0 \ell}$ are most commonly made using local velocity observations in the familiar logarithmic relation between the shear velocity $u_{*}$ and the variation of velocity $u$ with height $z$ above the bed

$$
\frac{u}{u_{*}}=\frac{1}{\kappa} \ln \left(\frac{z}{z_{0}}\right)
$$

where $u_{*}=\left(\tau_{0 \ell} / \rho\right)^{1 / 2}, \rho$ is fluid density, $\kappa$ is von Karman's constant (taken to be 0.40 ), and $z_{0}$ is the bed roughness length corresponding to $u=0$. Dimensional arguments and empirical observation show that (1) applies within a near-bed region that is both well below the free surface and above the local influence of individual bed roughness elements. Approximating this region as $3 D_{p}<z<h / 5\left(D_{p}\right.$ is the grain size for which $p$ percent of the bed is finer, with $p$ typically $\geq 84$ ), it is seen that the log region becomes small or nonexistent for $h / D_{p}$ $<15$. For steady uniform subcritical flow in wide straight channels with roughness dominated by grains on the bed surface a $\log$ profile is found to closely approximate velocity throughout the flow depth [e.g., Ferro and Baiamonte, 1994] (also data of Tominaga and Nezu [1992]). In these cases, the region to which (1) is applied may be extended to larger $z$ for the typical precision of field data, provided observations of $u$ throughout the flow depth confirm that a log profile exists.

Single observations of $u$ may be used in (1) to estimate $u_{*}$, 
Table 1. Description of Replicate Observations

\begin{tabular}{|c|c|c|c|c|c|c|}
\hline \multirow[b]{2}{*}{ Cross Section } & \multirow[b]{2}{*}{ Date } & \multirow[b]{2}{*}{$\begin{array}{c}\text { Discharge, } \\
\mathrm{m}^{3} / \mathrm{s}\end{array}$} & \multirow[b]{2}{*}{$\begin{array}{c}\text { Water } \\
\text { Surface } \\
\text { Elevation, } \\
\text { m }\end{array}$} & \multicolumn{3}{|c|}{ Number of Replicate Observations } \\
\hline & & & & $\begin{array}{c}\text { Near-Bed } \\
\text { Velocity } \\
\text { Profile }\end{array}$ & $\begin{array}{c}\text { Single } \\
\text { Near-Bed } \\
\text { Velocity }\end{array}$ & $\begin{array}{c}\text { Depth-Averaged } \\
\text { Velocity }\end{array}$ \\
\hline Poker bar 2 & May 29, 1991 & 67.1 & 31.47 & & & \\
\hline Poker bar 2 & May 30,1991 & 74.3 & 31.55 & 11 & 11 & 12 \\
\hline Poker bar 1B & April 27, 1993 & 80.5 & 31.51 & & & \\
\hline Poker bar 1B & April 28, 1993 & 79.7 & 31.52 & $\cdots$ & 10 & 12 \\
\hline Poker bar 2 & April 27, 1993 & 80.5 & 31.54 & & & \\
\hline Poker bar 2 & April 28, 1993 & 79.7 & 31.53 & $\cdots$ & 9 & 12 \\
\hline Steelbridge $3 \mathrm{C}$ & May 31, 1991 & 23.4 & 30.59 & & & \\
\hline Steelbridge 3C & June 1, 1991 & 23.3 & 30.58 & 11 & 11 & 11 \\
\hline Total & & & & 22 & 41 & 47 \\
\hline
\end{tabular}

termed here $u_{*_{z}}$. An independent estimate of $z_{0}$ is required, which may be estimated for gravel-bed rivers as $a D_{p} / 30$ [e.g., Hey, 1979; Whiting and Dietrich, 1990], where $a \approx 3$ for $p=$ 84. Using a single near-bed velocity observation is analogous to a Preston tube observation of $\tau_{0 \ell}$ [e.g., Ippen and Drinker, 1962; Nece and Smith, 1970]. Because only a single $(u, z)$ observation is required, estimates of $u_{*_{z}}$ are quick, offering considerable logistical advantage under conditions of variable flow, and require only a small log layer.

Most commonly, $\tau_{0 \ell}$ is estimated from (1) using multiple observations of $u$ in a single vertical. The slope of a least squares line fitted to $(u, \ln (z))$ is seen to be $u_{*} / \kappa$ from the derivative $\partial u / \partial(\ln (z))$ of (1). This estimate of $u_{*}$, termed $u_{* p}$, requires that a $\log$ profile hold over a finite range of $z$, so $u_{*_{p}}$ may be appropriately determined for a smaller range of flow conditions than $u_{*_{z}}$. The profile method offers two important advantages. The first is that no independent estimate of $z_{0}$ is needed because $u_{*_{p}}$ depends only on the slope of the profile and not its intercept. Second, some measure of the uncertainty in $u_{*_{p}}$ may be obtained from the standard error of the slope of the curve fitted between $u$ and $\ln (z)$, although careful consideration must be given to the proper treatment of error in both $u$ and $z$ [Wilkinson, 1984; Bauer et al., 1992].

The depth-averaged velocity $U$, rather than the point velocity $u$, may also be used to estimate $\tau_{0 \ell}$ using a friction factor or drag coefficient expression $C_{D} \propto\left(u_{*} / U\right)^{2}$. For nearly uniform flow in a wide channel with only grain-scale roughness an appropriate expression relating $U$ and $\tau_{0 \ell}$ is the depthintegrated form of (1)

$$
\frac{U}{u_{*}}=\frac{1}{\kappa} \ln \left(\frac{h}{e z_{0}}\right)
$$

where $e$ is the base of the natural logarithms. For the appropriate flow conditions an estimate of $u_{*}$, termed $u_{* h}$, may be found using (2) with observed values of $U$ and $h$ and an estimate of the bed roughness $z_{0}$. When both grain and bedform roughness exist, $u_{*_{h}}$ is the total drag composed of both form drag and skin friction; in this case, a drag partition is required to estimate the skin friction component of $\tau_{0 \ell}$ [e.g., Nelson and Smith, 1989; Wiberg and Smith, 1991].

\section{Precision of $\tau_{0 \ell}$ Estimates Under Field Conditions}

Because single observations are used to determine $u_{*_{z}}$ and $u_{*_{h}}$, an estimate of their uncertainty cannot be made directly, and replicate observations under constant conditions are needed to estimate precision. The replicate observations used here were made for nearly constant flow conditions during controlled reservoir releases on the Trinity River, a large gravel-bed river in northern California. $D_{50}$ at the studied sections varied between 22 and $44 \mathrm{~mm}$, and $D_{90}$ varied between 85 and $120 \mathrm{~mm}$. Depth-averaged flow velocity varied between 0.5 and $1.5 \mathrm{~m} / \mathrm{s}$, and flow depth varied between 0.75 and $2.6 \mathrm{~m}$. The velocity observations were made in straight reaches with relatively simple topography, so that the flow resistance was dominated by grain roughness. Velocity was measured with conventional field equipment (Price AA current meters mounted on handheld wading rods) deployed from rafts maneuvered across fixed cross sections using an anchored rope and pulley system [Wilcock et al., 1996]. Observation time for individual velocity measurements was $40-60 \mathrm{~s}$. Flow depth was read directly off the wading rod, and the current meter was moved between elevations without moving the rod.

Discharge was monitored using velocity observations across entire cross sections and by tracking stage on staff plates placed along one bank. Bed movement was tracked using tracer gravels, bed-load traps, and direct observation of the bed surface. The flows examined here produced only slight bed mobilization, so that the bed surface was essentially immobile over the period between replicate observations [Wilcock et al., 1996]. Replicate observations were made at identical locations on consecutive days with little or no change in stage and discharge (Table 1). Therefore, the calculated error includes that effect of relocating the wading rod on an uneven bed.

Depth-averaged velocity $U$ was calculated as the depth average of a least squares line fitted between $u$ and $\ln (z)$ for each velocity profile. Replicates of $U$ were possible in 47 cases, each with a minimum of four $u$ observations. Replicates of $u$ at identical near-bed elevations were possible in 41 cases, 22 with $z=15 \mathrm{~cm}$ and 19 with $z=0.2 h$, for which $0.25 \mathrm{~m}<z<0.5$ $\mathrm{m}$. In 22 cases, replicate observations were made of at least six point velocities in the lower one half of the flow.

Estimates of $u_{*}$ were made using (1) with a single $(u, z)$ observation in the lower $20 \%$ of the flow $\left(u_{*_{z}}\right)$, using (2) with the observed flow depth and depth-averaged velocity $\left(u_{*_{h}}\right)$, and from the slope of the least squares fit to at least six observations of $(u, \ln (z))$ in the lower half of the flow depth $\left(u_{*_{p}}\right)$. In the first two cases an independent estimate of $z_{0}$ is needed and was calculated using $z_{0}=a D_{90} / 30$. Visual estimates of $D_{90}$ were made before and after the release for an area of approximately $1.0 \mathrm{~m}^{2}$ around each sample location. 


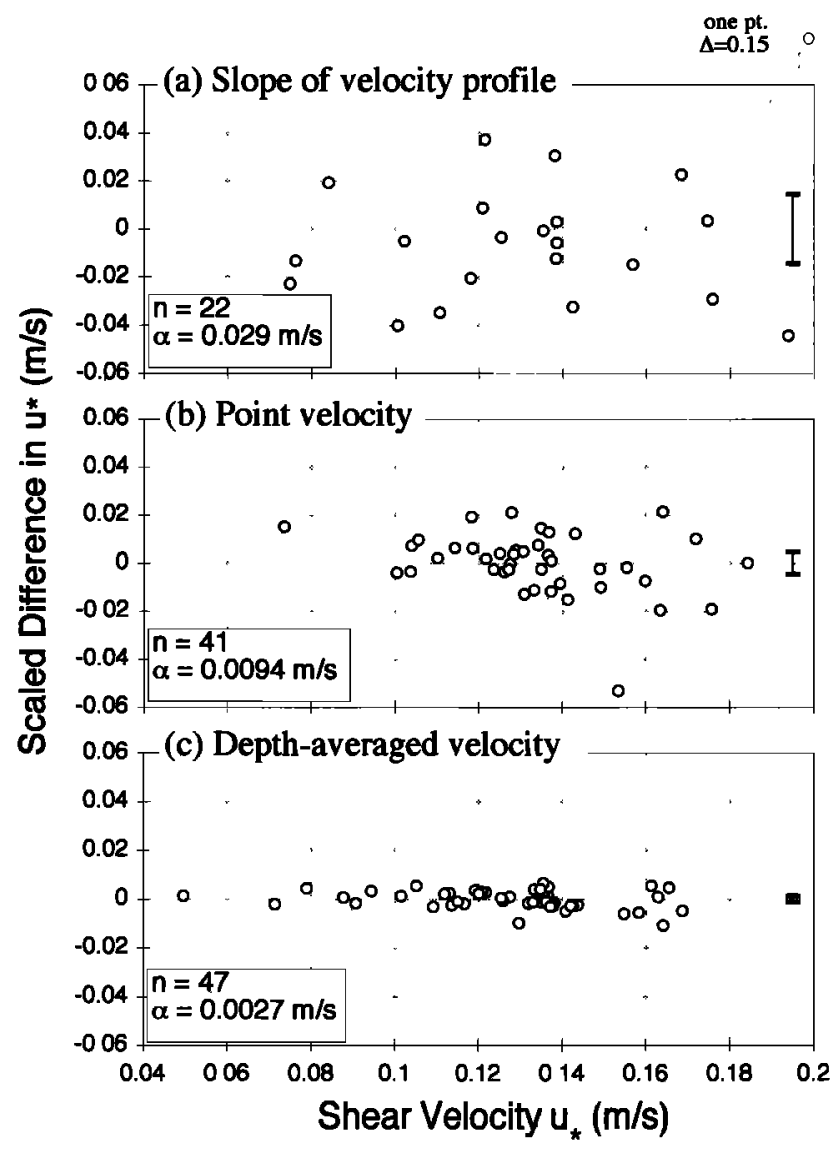

Figure 1. Differences between replicate calculations of $u_{*}$ for three different methods: (a) slope of velocity profile (1) in lower half of flow, (b) a single velocity observation in the lower $20 \%$ of the flow and (1), and (c) depth-averaged velocity and (2). Difference in $u_{*}$ plotted as a function of mean $u_{*}$ for each replicate pair. Differences do not depend strongly on magnitude of $u_{*}$. Standard errors $\alpha\left(u_{*}\right)$ are calculated from (3).

$D_{90}$ was assigned within a $1 / 2 \phi$ size fraction (giving $D_{90}$ within a factor of $\approx 1.2$ ) following calibration with pebble counts along each section. A value of $a=2.85$ was found to minimize the squared difference between $u_{*_{h}}$ and the roughness-independent $u_{*_{p}}$ for 75 velocity profiles. A value of $a=2.85$ corresponds to $z_{0}=0.095 D_{90}$, which is essentially identical to $z_{0}$ $=0.1 D_{84}$ found by Whiting and Dietrich [1990] and $z_{0}=$ $0.09 D_{84}$ found by Wiberg and Smith [1991].

\section{Replicate Observations of $\boldsymbol{u}_{*}$}

Replicate $u_{*}$ values are plotted in Figure 1 as the difference between each repeated estimate of $u_{*}$. The difference is plotted as a function of the mean $u_{*}$ for each replicate pair. To account for small differences in total discharge or stage between days with replicate observations, the difference between replicate pairs is calculated as $\left(u_{*_{1}}-u_{*_{2}}-\Delta_{d}\right)$, where $\Delta_{d}$ is the mean difference $\left(u_{*_{1}}-u_{*_{2}}\right)$ for all observations on a given pair of days. This scaled difference adjusts for slight changes in the mean flow to permit comparison of the replicate differences for all days. Because the variance of the difference between two observations of a random variable $X$ is $\operatorname{Var}\left(X_{1}\right.$ $\left.X_{2}\right)=2 \operatorname{Var}(X)$, a standard error of estimate $\alpha\left(u_{*}\right)$ may be calculated from the replicate estimates as

$$
\alpha\left(u_{*}\right)=\sqrt{\frac{1}{2} \operatorname{Var}\left(u_{* 1}-u_{* 2}-\Delta_{d}\right)}
$$

where $\operatorname{Var}\left(u_{* 1}-u_{* 2}-\Delta_{d}\right)$ is the variance of the scaled differences. Because Var $(X-$ const $)=\operatorname{Var}(X),(3)$ applied to all observations on a replicate pair of days gives $\alpha\left(u_{*}\right)$ for that day. When applied to all replicate observations the scaled difference adjusts for slight mean differences between replicate days when combining all observations in a single estimate of $\alpha\left(u_{*}\right)$.

For each of the three estimates, $\alpha\left(u_{*}\right)$ appears to be relatively insensitive to the magnitude of $u_{*}$ over the threefold range of $u_{*}$ (Figure 1). For $u_{*_{h}}$ the standard error $\alpha\left(u_{*_{h}}\right)=$ $0.27 \mathrm{~cm} / \mathrm{s}$, or an average of $2.4 \%$ of $u_{*}$. This error is roughly one third that of $u_{*_{z}}$, which is $\alpha\left(u_{*_{z}}\right)=0.94 \mathrm{~cm} / \mathrm{s}$, or an average of $7.0 \%$ of $u_{*}$. The error associated with $u_{* p}$ is much larger, $\alpha\left(u_{*_{p}}\right)=2.9 \mathrm{~cm} / \mathrm{s}$, or an average of $18.3 \%$ of $u_{*}$. Large uncertainty in $u_{*_{p}}$ has been noted by previous workers [e.g., Whiting and Dietrich, 1990; Pitlick, 1992].

\section{Sources of Error}

The smaller error for $u_{*_{h}}$ is presumably due to smaller error in $U$ or $h$ relative to $u$ or $z$. Standard errors of $u, U$, and $h$ may be estimated from the replicate observations and the corresponding forms of (3). The scaled differences for $u, U$, and $h$ are shown in Figure 2, and the standard errors $\alpha_{u}, \alpha_{U}$, and $\alpha_{h}$ are given in Table 2. The sample size for $u$ is increased by including all replicate observations at identical elevations in the lower one half of the flow. The point velocity error $\alpha_{u}$ is nearly 3 times $\alpha_{U}$, which is consistent with the larger sample size used to determine $U$ and supports the conclusion that $\alpha\left(u_{*_{h}}\right)$ is smaller than $\alpha\left(u_{*_{z}}\right)$ because of the corresponding error associated with single observations of $u$.

The contribution of each of these errors to uncertainty in $u_{*}$ may be approximated using the linear error propagation formula [e.g., Topping, 1972, p. 82; Bevington and Robinson, 1992, p. 43]. This helps to identify the sources of error in $u_{*}$, suggests methods for decreasing uncertainty in $u_{*}$, and provides a basis for estimating error in $u_{*}$ from measurements made under similar circumstances. Equation (1) may be arranged in the form $u_{*_{z}}=\kappa u / \xi_{z}$, and (2) may be arranged as $u_{*_{h}}=\kappa U / \xi_{h}$, where $\xi_{z}=\ln \left[30 z /\left(a D_{p}\right)\right]$ and $\xi_{h}=\ln \left[11 h /\left(a D_{p}\right)\right]$. Expressed in proportional form, the standard error for $u_{*_{z}}$ is

$$
\frac{\alpha\left(u_{* z}\right)}{u_{* z}}=\sqrt{\left(\frac{\alpha_{u}}{u}\right)^{2}+\left(\frac{\alpha_{z}}{z \xi_{z}}\right)^{2}+\left(\frac{\alpha_{D_{p}}}{D_{p} \xi_{z}}\right)^{2}}
$$

and the standard error for $u_{*_{h}}$ is

$$
\frac{\alpha\left(u_{* h}\right)}{u_{* h}}=\sqrt{\left(\frac{\alpha_{U}}{U}\right)^{2}+\left(\frac{\alpha_{h}}{h \xi_{h}}\right)^{2}+\left(\frac{\alpha_{D_{p}}}{D_{p} \xi_{h}}\right)^{2}}
$$

The standard errors $\alpha_{u}, \alpha_{U}$, and $\alpha_{h}$ are taken from the replicate observations. Because $z$ is specified, an independent estimate of $\alpha_{z}$ cannot be made and is assumed to equal $\alpha_{h} / 2$, based on the reasoning that both $z$ and $h$ are subject to error in placing the rod on an uneven bed, whereas $z$ is specified exactly and uncertainty in $h$ also arises from error in determining the free surface elevation. Other plausible values of $\alpha_{z}$ were found to have only a minor influence on the value of $\alpha\left(u_{*_{z}}\right)$ from (4). The value of $\alpha_{D_{p}}$ was taken to be $D_{90} / 16$, which corresponds to $95 \%$ confidence that the true $D_{90}$ falls within a range of $1.3 D_{90}$. When used with (4) and (5) and the values and error associated with the replicate observations of 

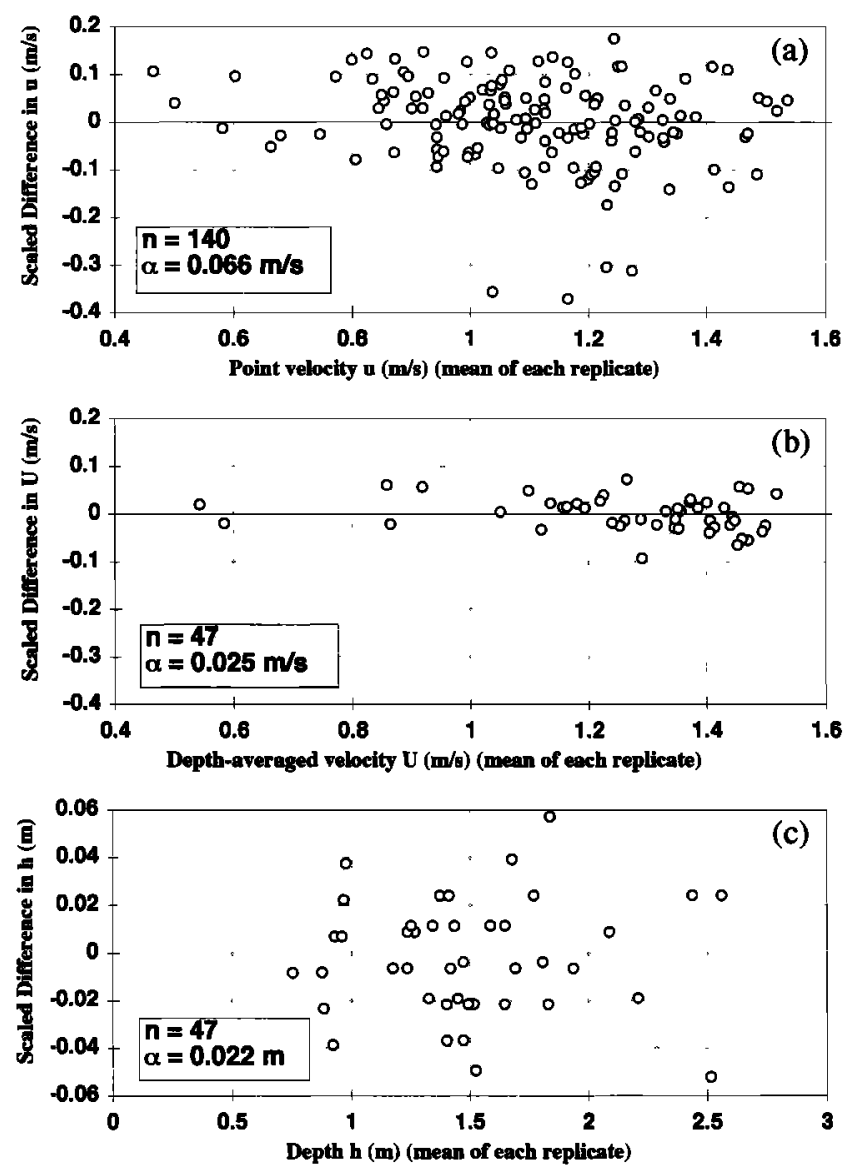

Figure 2. Differences between replicate observations of (a) near-bed point velocity, (b) depth-averaged velocity, and (c) flow depth. Differences are plotted as a function of mean for each replicate pair; differences do not depend strongly on magnitude. Standard errors $\alpha$ are calculated from (3).

$u, U$, and $h$, these estimates of $\alpha_{z}$ and $\alpha_{D_{p}}$ produce values of $\alpha\left(u_{*}\right)$ that are comparable to those found from the $u_{*}$ replicates. The mean of $\alpha\left(u_{*}\right)$ calculated for all replicate cases using (4) and (5) are given in Table 2 . There is little difference

Table 2. Standard Errors From Replicate Observations

\begin{tabular}{|c|c|c|c|}
\hline Variable & $\begin{array}{c}\text { Standard } \\
\text { Error From } \\
\text { Replicate } \\
\text { Observations }\end{array}$ & $\begin{array}{l}\text { Number of } \\
\text { Replicates }\end{array}$ & $\begin{array}{c}\text { Alternative } \\
\text { Estimate } \\
\text { of } \\
\text { Standard } \\
\text { Error in } \\
u_{*}\end{array}$ \\
\hline$u_{* z}, \mathrm{~m} / \mathrm{s}$ & 0.0094 & 41 & $0.0093^{a}$ \\
\hline$u_{* h}, \mathrm{~m} / \mathrm{s}$ & 0.0027 & 47 & $0.0033^{b}$ \\
\hline$u_{* p}, \mathrm{~m} / \mathrm{s}$ & 0.0291 & 22 & $0.0210^{c}$ \\
\hline$u, \mathrm{~m} / \mathrm{s}$ & 0.0661 & 140 & \\
\hline$U, \mathrm{~m} / \mathrm{s}$ & 0.0253 & 47 & \\
\hline$h, \mathrm{~m}$ & 0.0218 & 47 & \\
\hline
\end{tabular}

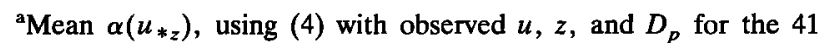
replicate cases; $\alpha_{z}=\alpha_{h} / 2, \alpha_{D_{p}}=D_{p} / 16, \alpha_{u}=0.0661 \mathrm{~m} / \mathrm{s}$, and $\alpha_{h}$ $=0.0218 \mathrm{~m}$.

bMean $\alpha\left(u_{*_{h}}\right)$, using (5) with observed $U, h$, and $D_{p}$ for the 47 replicate cases; $\alpha_{D_{p}}=D_{p} / 16, \alpha_{U}=0.0253 \mathrm{~m} / \mathrm{s}$, and $\alpha_{h}=0.0218$ m.

${ }^{c}$ Mean standard error on regression slope between $u$ and $\ln (z)$ for 78 profiles with $\geq 6$ observations in the lower half of flow depth.
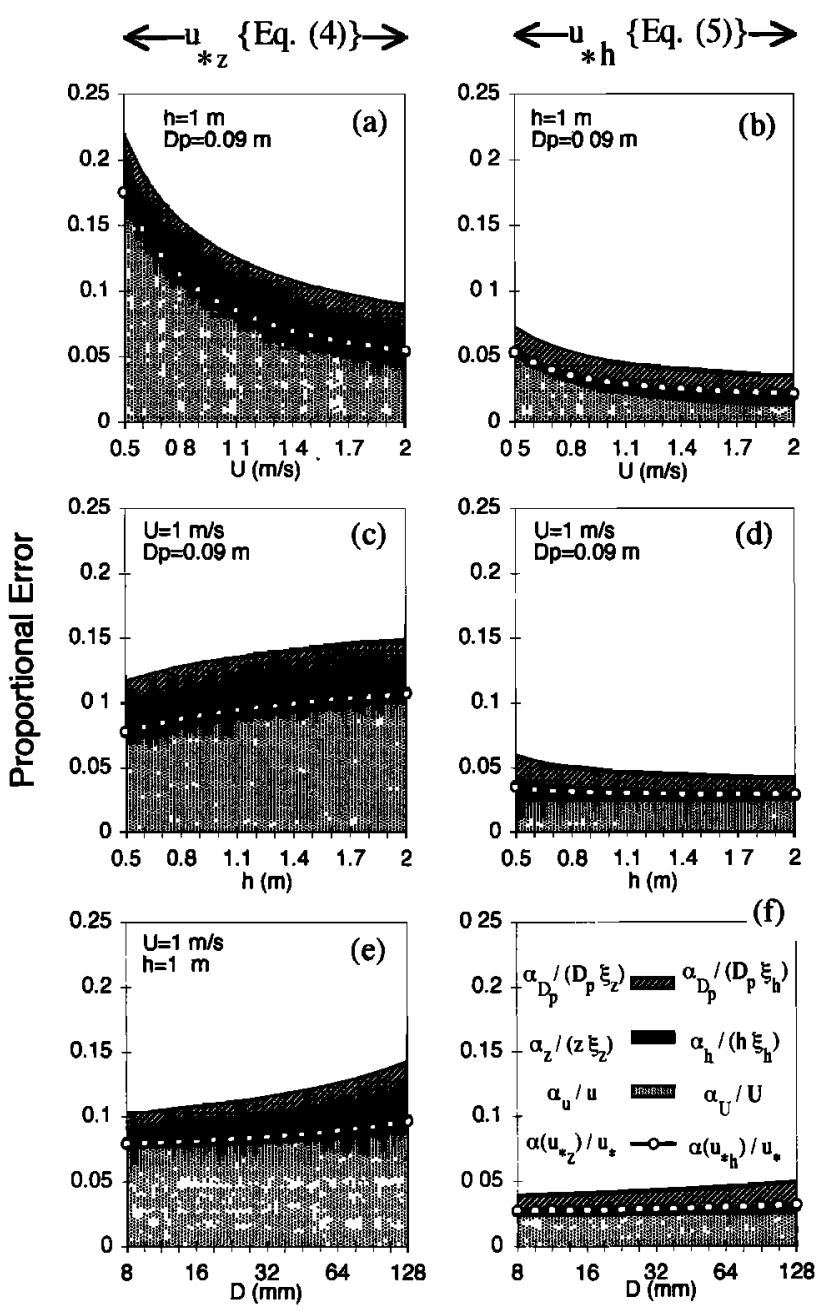

Figure 3. Components of error in estimating $u_{*}$ from observed or assumed errors in $u, U, z, h$, and $D_{p}$, as a function of (a) and (b) $U$, (c) and (d) $h$, and (e) and (f) $D$. Left column (Figures 3a, 3c, and 3e) gives proportional error $\alpha\left(u_{*_{z}}\right) / u_{*_{z}}$ for $z=0.15 \mathrm{~m}$, calculated from (4), along with individual terms on the right side of (4). Right column (Figures 3b, 3d, and 3f) gives proportional error $\alpha\left(u_{*_{h}}\right) / u_{*_{h}}$ calculated from (5), along with individual terms on the right side of (5). Values of $\alpha_{u}, \alpha_{U}$, and $\alpha_{h}$ are from replicate observations (see Table 2); $\alpha_{z}=\alpha_{h} / 2 ; \alpha_{D_{p}}=D_{p} / 16$. Error in $u$ dominates $\alpha\left(u_{*_{z}}\right)$ which is approximately $2.2-3.7$ times larger than $\alpha\left(u_{*_{h}}\right)$.

between the two estimates of error in $u_{*}$, suggesting that the component errors and the form of (4) and (5) are correct.

It may be seen from (4) and (5) that the values of $\alpha\left(u_{*_{z}}\right)$ and $\alpha\left(u_{* h}\right)$ depend not only on the error associated with $u, U$, $z, h$, and $D_{p}$ but also on their magnitude. Figure 3 presents the variation of $\alpha\left(u_{*_{z}}\right)$ and $\alpha\left(u_{*_{h}}\right)$ with $U, h$, and $D_{p}$. Values of $u$ used in Figure 3 are calculated using (1) with $z=0.15 \mathrm{~m}$, and $u_{*}$ is found from (2) using $z_{0}=0.095 D_{90} . U=1 \mathrm{~m} / \mathrm{s}$, $h=1 \mathrm{~m}$, and $D_{p}=0.09 \mathrm{~m}$ are used as common values among the various panels of Figure 3. Also shown on Figure 3 are the individual terms on the right-hand side of (4) and (5), which are the proportional component errors due to $u, U, z, h$, and $D_{p}$. Except at large values of $U$, for which the three terms in (4) are comparable in magnitude, error in $u_{*_{z}}$ is dominated by the first term in (4), which is the error associated with $u$. Error in $U$ is smaller, so that error in $u_{* h}$ results primarily from error 


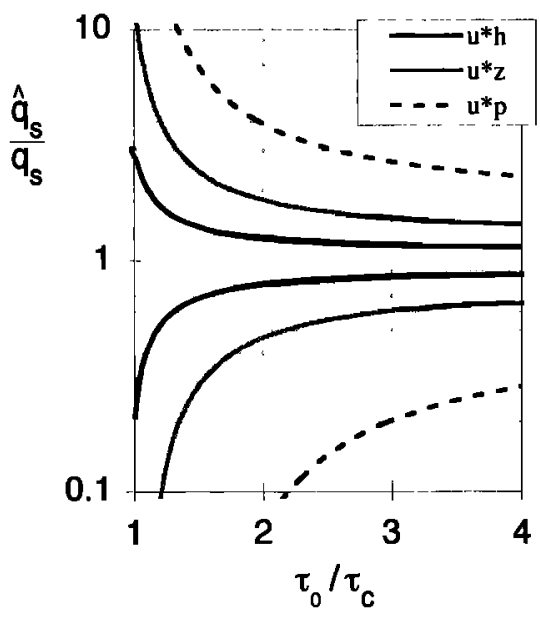

Figure 4. Error in calculated transport rate associated with $\pm \alpha$ uncertainty in $u_{*}$, expressed as a ratio of the transport rate $\hat{q}_{s}$ calculated using $u_{*} \pm \alpha$ and the transport rate $q_{s}$ using $u_{*}$. Error values used are $2.4 \%$ for $u_{* h}, 7.0 \%$ for $u_{*_{z}}$, and $18.3 \%$ for $u_{* p}$.

in both $U$ and $D_{p}$. The value of each individual term in (4) is larger than the equivalent term in (5) at all values of $U, h$, and $D_{p}$, and the total error $\alpha\left(u_{*_{z}}\right)$ is 2.2-3.7 times larger than $\alpha\left(u_{* h}\right)$, with a mean of 3.0 for the cases shown in Figure 3. Error in $u_{*_{h}}$ is less than $5 \%$, with a mean of $3 \%$. Error in $u_{*_{z}}$ is between 5 and more than $15 \%$, with a mean of $9 \%$. This relative magnitude of error is comparable to the values found from the replicate estimates of 2.4 and $7.0 \%$ for $u_{*_{h}}$ and $u_{*_{z}}$, respectively.

The standard error $\alpha\left(u_{*_{p}}\right)$ from the slope $\partial u / \partial(\ln z)$ of (1) may be estimated using the standard error for the calculated regression slope $\left(\alpha\left(u_{* p}\right)=\kappa \alpha\left[u_{*} / \kappa\right]\right)$ for each velocity profile. The mean standard error for 78 profiles with at least six observations in the lower half of the flow depth is $\alpha\left(u_{*_{p}}\right)=$ $0.0210 \mathrm{~m} / \mathrm{s}$, which is somewhat smaller than the value of $0.0291 \mathrm{~m} / \mathrm{s}$ found from the 22 replicate samples but considerably larger than any of the error estimates for $u_{*_{h}}$ and $u_{*_{z}}$.

\section{Discussion and Summary}

The standard error $\alpha\left(u_{*_{h}}\right)$ for estimates of $u_{*}$ using flow depth and depth-averaged velocity in (2) is 2 to 3 times smaller than the standard error $\alpha\left(u_{*_{z}}\right)$ for estimates using single velocity observations and (1). The primary reason for this difference is the comparable difference in error associated with using a single observation of $u$ as opposed to using multiple observations to find $U$. An additional factor is that the proportional error in $h$ is likely to be much smaller than that in $z$. The standard error $\alpha\left(u_{*_{p}}\right)$ for $u_{*}$ estimated from the slope $\partial u / \partial(\ln z)$ is 2 to 3 times larger than the standard error $\alpha\left(u_{*_{z}}\right)$ based on (1). The difficulty in obtaining precise $u_{*}$ estimates from the slope of a velocity profile has been noted previously [Wilkinson, 1984; Dietrich and Whiting, 1989].

Using $\pm \alpha\left(u_{*}\right) / u_{*}$ to represent the uncertainty in $u_{*}$, proportional errors of $\pm 2.4,7.0$, and $18.3 \%$ in $u_{*_{h}}, u_{*_{z}}$, and $u_{*_{p}}$ correspond to errors in $\tau_{0 \ell}$ of approximately $\pm 5,14$, and $37 \%$. Error in estimated $\tau_{0 \ell}$ can produce large errors in the calculated transport rate. This is shown on Figure 4, which shows the range in transport rates resulting from $\pm \alpha$ error in $u_{*}$, as a function of $\tau_{0 e} / \tau_{c}$, where $\tau_{c}$ is the critical $\tau_{0 \ell}$ for incipient grain motion. The transport relation of Parker [1979] is used, although similar conclusions would be drawn from other transport relations. The error in calculated transport rate increases with decreasing $\tau_{0}$. Order-of-magnitude error occurs for $\tau_{0} / \tau_{c}$ $<1.5$ with $u_{*_{z}}$ and for $\tau_{0} / \tau_{c}<3.4$ with $u_{* p}$. It is unlikely that the error associated with $u_{*_{p}}$ can permit reliable estimates of local transport rate.

Although estimates of $u_{*}$ from (2) are the most precise, the range of conditions under which this method may be used are limited to cases of wide, shallow flow in straight channels with simple roughness, for which (1) may be expected to hold approximately throughout the flow depth. If only grain-scale roughness exists, (2) provides an estimate of the local skin friction. If bed forms exist (and take up a small fraction of the flow depth), (2) may be used to estimate the total $\tau_{0 \ell}$, and a drag partition is needed to estimate the local skin friction. Uncertainty in the magnitude of the form drag can be a significant and poorly known source of error in $\tau_{0 \ell}$. Although the applicable conditions for $u_{*_{h}}$ appear restrictive, they are not uncommon. Such flow conditions are sought for the purpose of gaging stream discharge from measurements of $U$ and $h$ across the section. For these cases, (2) may be used to determine $\tau_{0 \ell}$, and from that the local and section-integrated transport rates may be determined. It is important that $U$ be determined from a number of $(u, z)$ observations throughout the water column (rather than, for example, a single observation at $0.4 h$ ) in order to decrease the error in estimating $U$ and provide a check on the appropriateness of (2).

Estimates of $u_{*_{z}}$ using a single velocity observation in (1) have a larger error than $u_{*_{h}}$, primarily because the error associated with a single observation of $u$ is roughly 3 times larger than that associated with measurement of $U$ from many individual $(u, z)$ observations. The principle advantages of this method are that it is quick, allowing many observations in spatially or temporally variable flows, and that $u$ can be measured close to the bed within a log layer dominated by grain roughness [Whiting and Dietrich, 1990]. The precision of this estimate can be improved by making repeated or lengthy observations of $u$, thereby decreasing its uncertainty. Although this eliminates much of the advantage of having a quick method, it preserves the advantage of making measurements only very close to the bed.

Estimates of $u_{*}$ from the slope of the velocity profile are the least precise of the three methods examined here. Nonetheless, this method has the advantages that an independent estimate of the bed roughness $z_{0}$ is not required and an estimate of the error in $u_{*_{p}}$ can be routinely developed using the standard error of the fitted regression between $u$ and $\ln (z)$. Beyond its lack of precision the main disadvantage of this method is that velocity observations are required over a finite range of $z$ within the log layer, which can be vanishingly small in flows with large relative roughness. The requirement for a finite log layer also makes the method less adaptable to flows that vary rapidly in space or time.

The methods discussed here do not apply under all conditions. Of particular importance is the case of large relative roughness $\left(D_{p} / h\right.$ greater than approximately 0.2$)$, for which wakes dominate the entire flow field, making the vertical velocity profile non log linear so that (1) no longer holds [e.g., Jarrett, 1990; Pitlick, 1992]. Interestingly, it has been observed that (2) may apply to conditions of large relative roughness for which (1) clearly does not hold. In applying their velocity model to a wide range of $D_{84} / h$ and sediment sorting, Wiberg 
and Smith [1991] found $U / u_{*}$ to be accurately represented by an expression essentially identical to (2) for $D_{84} / h \leq 1.0$, even though the predicted velocity profiles for $D_{84} / h>0.1$ were distinctly curved in the near-bed region. This result is for a spatially averaged velocity profile, however. No simple relation between $U$ and $\tau_{0 \ell}$ exists for the strongly spatially variable flow with large relative roughness.

Both $u_{*_{h}}$ and $u_{*_{z}}$ require an independent estimate of the boundary roughness $z_{0}$. If the size distribution of the bed is unknown, neither can be used to estimate $\tau_{0 \ell}$, leaving $u_{*_{p}}$ as the only alternative. In this case, it is necessary to measure the velocity profile as accurately as possible (e.g., by using multiple observations with an array of small current meters), although the resulting uncertainty may still be too large to make useful calculations of sediment transport rates.

Acknowledgments. Field work on the Trinity River was supported by the U.S. Fish and Wildlife Service, Trinity River Flow Study, under a cooperative agreement with the Johns Hopkins University (14-160001-91514). Additional funding was provided by the Southern California Edison Company. The velocity observations were collected by Alan Barta, Matt Kondolf, Graham Matthews, John Pitlick, Conor Shea, and Mark van Steeter. Earlier drafts of the manuscript were improved by comments from John Pitlick, Peter Whiting, and Ellen Wohl.

\section{References}

Bauer, B. O., D. J. Sherman, and J. F. Wolcott, Sources of uncertainty in shear stress and roughness length estimates derived from velocity profiles, Prof. Geogr., 44(4), 453-464, 1992.

Bevington, P. R., and D. K. Robinson, Data Reduction and Error Analysis for the Physical Sciences, 2nd ed., 328 pp., McGraw-Hill, New York, 1992.

Dietrich, W. E., and P. J. Whiting, Boundary shear stress and sediment transport in river meanders of sand and gravel, in River Meandering, Water Resour. Monogr., vol. 12, edited by S. Ikeda and G. Parker, pp. 1-50, AGU, Washington, D. C., 1989.

Ferro, V., and G. Baiamonte, Flow velocity profiles in gravel-bed rivers, J. Hydraul. Eng., 120(1), 60-80, 1994.
Hey, R. D., Flow resistance in gravel-bed rivers, J. Hydraul. Div. Am. Soc. Civ. Eng., 105(4), 365-379, 1979.

Ippen, A. T., and P. A. Drinker, Boundary shear stress in curved trapezoidal channels, J. Hydraul. Div. Am. Soc. Civ. Eng., 88(5), 143-179, 1962.

Jarrett, R. D., Hydrologic and hydraulic research in mountain rivers, Water Resour. Bull., 26, 419-429, 1990.

Nece, R. E., and J. D. Smith, Boundary shear stress in rivers and estuaries, J. Water. Harbors Coastal Eng. Div. Am. Soc. Civ. Eng., 96(2), 335-358, 1970

Nelson, J. M., and J. D. Smith, Flow in meandering channels with natural topography, in River Meandering, Water Resour. Monogr., vol. 12 , edited by S. Ikeda and G. Parker, Pp. 69-102, AGU, Washington, D. C., 1989.

Parker, G., Hydraulic geometry of active gravel rivers, J. Hydraul. Div. Am. Soc. Civ. Eng., 105(9), 1185-1201, 1979.

Pitlick, J., Flow resistance under conditions of intense gravel transport, Water Resour. Res., 28(3), 891-903, 1992.

Tominaga, A., and I. Nezu, Velocity profiles in steep open-channel flows, J. Hydraul. Eng., 118(1), 73-90, 1992.

Topping, J., Errors of Observation and Their Treatment, 199 pp., Chapman and Hall, New York, 1972.

Whiting, P. J., and W. E. Dietrich, Boundary shear stress and roughness over mobile alluvial beds, J. Hydraul. Eng., 116(12), 1495-1511, 1990.

Whiting, P. J., and W. E. Dietrich, Convective accelerations and boundary shear stress over a channel bar, Water Resour. Res., 27(5), 783-796, 1991

Wiberg, P. L., and J. D. Smith, Velocity distribution and bed roughness in steep streams, Water Resour. Res., 27(5), 825-838, 1991.

Wilcock, P. R., A. F. Barta, C. C. Shea, G. M. Kondolf, W. V. G. Matthews, and J. C. Pitlick, Observations of flow and sediment entrainment on a large gravel-bed river, Water Resour. Res., 32, 2897-2909, 1996.

Wilkinson, R. H., A method for evaluating statistical errors associated with logarithmic profiles, Geo. Mar. Lett., 3, 49-52, 1984.

P. R. Wilcock, Department of Geography and Environmental Engineering, Johns Hopkins University, Baltimore, MD 21218. (e-mail: wilcock@jhu.edu)

(Received May 2, 1996; revised July 17, 1996; accepted July 23, 1996.) 